\title{
E-Learning and the Challenges faced by Teachers during the Pandemic Period in Ipueiras - Ceará.
}

\author{
Francisco Samuel Gomes de Araújo ${ }^{1}$ \\ Glauciana Alves Teles ${ }^{2}$
}

\begin{abstract}
Distance education in Brazil is not recent. Although its beginnings date back to the first half of the 20th century, public policies on distance education began in the country in the 1960s and 1970s. Then, in the 1990s, the law 9394/96 (National Education Guidelines and Framework Law, LDB) was the frontier that established the legality for e-learning at various educational levels. From this perspective, this article aims to analyze the educational measures implemented during the pandemic period, more specifically the e-learning and its impacts on teachers' work from the public schools in Ipueiras/CE. It is descriptive and exploratory research, which has as theoretical reference Alves (2009), Neto(2012), Kenski(2013), Tardif(2014), Carrara(2016), Marcílio(2019), and Wojcicki (2019).The analysis method consisted of collecting information through Google Forms, reviewing the literature, collecting and organizing data, besides analyzing and discussing the information presented. It is notorious the importance of e-learning to recreate learning environments that allow a significant interaction among students, not distancing themselves from their position as citizens with its particularities. In a holistic view, however, this interaction should be more than between student and teacher but also among students themselves and with computers, fostering their autonomy, creativity, and improving social interactions among the entire school community. The challenges in this way of teaching are the classes centered on the teacher and the difficulty to access technological resources by teachers and students.
\end{abstract}

Keywords: Teacher training. E-learning. Distance education. Pandemic.

\section{Introduction}

The rapid technological development, observed since the second half of the 20th century, has been changing the way of teaching and learning. Most of these transformations result from digital technological innovation that has developed rapidly, transforming not only man as a society but also the educational culture. However, with technological innovations, e-learning is now understood as a form of education capable of offering possibilities of access to it at different levels, aiming at its democratization in the country. Such recommendations are from in the Lei de Diretrizes e Bases da Educação (National Education Guidelines and Framework Law, LDB)n 9.394, of December 20, 1996.

In general, the interactive and collaborative relationship is fundamental in teaching and learning, becoming the defense argument for e-learning. These educational modalities can foster innovation in teachers' learning practices and strategies, building a structure centered on teaching, research, and social constructivist actions, developing curiosities, and integrating teamwork and cooperative learning to value the interaction between students so that all participate actively.

In the same way, the changes in the educational context and their acceptance by the teachers meet resistance and conflict. However, the current process of expansion of e-learning and technological innovation in teaching has brought effects in the initial and continuing training of teachers. Therefore, these new transformations have characterized different constructions and paradigms in school organization, in which the teacher comes across problems usually in the initial or continued education in the contemporary world.

The training of teachers in the molds of e-learning is recent and still in consolidation. In Brazil, distance education at different educational levels began to be encouraged in the early 2000s. This fact corresponds to the expansion of access to the internet and to computer systems networks, which became part of teaching and research institutions. Thus, this research is justified through the application of educational measures in contribution to its target audience, considering the use of distance education, as well as e-learning, especially during the pandemic crisis.

\footnotetext{
${ }^{1}$ Graduatestudent in the department of geographyofUniversidadeEstadual Vale do Acaraú (Acaraú Valley State University, UVA). samuelipueiras@hotmail.com

${ }^{2} \mathrm{PhDinhumangeography.Professor}$ in the undergraduate (licentiateandbachelor's degrees) and graduate geography coursesatUVA, Sobral/CE. glauciana_teles@uvanet.br
} 
The starting point was to identify challenges faced by teachers regarding the educational measures for e-learning during the pandemic period, highlighting the municipality of Ipueiras-CE. Even with technology delivering opportunities for improving education, there are some challenges in this new way of teaching, such as classes focused on the teacher and the difficulty for teachers and students to access technological requirements. Therefore, here is an attempt to answer the following question: what are the impacts of the e-learning implementation in public schools in Ipueiras during the Covid-19 pandemic?

Initially, there is the presentation of a historical survey of distance education up to the present day, in Brazil and the world. Then, e-learning and its contribution to distance learning are discussed, establishing the difference between these two educational modalities. Therefore, it is necessary to analyze the challenges faced by teachers concerning educational measures in e-learning during the pandemic period.

It is descriptive and exploratory research because it proposes the identification challenges faced by teachers regarding e-learning and, from this data, proposes discussions to understand the reality. As an analysis method, it is proposed (1) the development of a tool for the collection of information from teachers, through Google Forms, (2) literature review, (3) gathering and organization of data from May to June 2020, and (4) analysis and discussion of data.

The work presented here has three sections, the first presenting Brazilian education in the distance education context. The second is a brief history of its existence in the world and Brazil. At last, it is the analysis obtained through the questionnaire with teachers from public schools in Ipueiras, aiming to answer the problem presented previously.

\section{Brazilian Education in a Distance Education Context}

It is necessary to consider that Brazilian education in the context of distance education is expanding today. Some people say that it has been gaining relevant space in the Brazilian educational context, requiring regulations and laws that facilitate access to this modality. On the other hand, Saviani (2013) shows that the historical development of the Brazilian educational process has been providing relevant elements to understand education, as well as to carry it out in practice.

In this context, it is evident that it stands out as a differential in social insertion in the attainment of higher education by all classes of people around the country. For Carrara (2016), it is no exaggeration to state that the curriculum gains relevance in the training of education professionals, especially after the promulgation of the LDB No. 9394, ratified on December 20, 1996.

As highlighted above, it is interesting to note that people interested in education have seen both digital information and communication technology (DTICs) and distance education as a new opportunity to rethink the improvement of teaching. However, there is one fact that overlaps with the incorporation of new technology in the formulation of educational systems and school curricula, which is accessibility, since the subjects of this process - the school and academic community - must be part of the activities proposed in virtual learning environments (VLEs).

According to Kenski (2013), contemporary culture has to do with the idea of interactivity, interconnection, and interrelationship between people. Thus, it is of particular importance that a large part of these changes stems from the digital technology innovations that have developed rapidly, transforming not only man as a social being but also the culture. Therefore, as Carrara (2016) points out, the regulations at e-learning are significant to make the academic curriculum attractive to the new condition of distance education. Concerning the training of teachers, the transformations make one remind of Tardif $(2014$, p.17) when it states that the teachers' knowledge carries within itself the marks of their work, which is not only a tool but whose responsible for its production and modeling is the work in itself.

The formation of teachers in the current model of distance education provides the need to rethink the pedagogical processes to satisfy the students. It is essential to consider, for example, that e-learning can solve structural problems in education, such as geographical distances and lack of teachers in various areas of knowledge. As explained above, it is pertinent to bring up that e-learning, together with TDICs, has been making the teacher as a mediator, a key player in the different professional spaces. Besides, with the increasing expansion, e-learning now has a global reach (MOORE; KEARSLEY, 2007). In other words,

To train teachers with a high-quality theoretical and practical knowledge to act on multiple fronts beyond the traditional spaces of regular education - such as distance education, education mediated by technologies, and cooperative education, inclusive entrepreneurship - is a need that the new culture and society require (KENSKI, 2013, p. 91).

Given the above, the author makes clear the need for the teacher to make changes in their practices and habits. In this sense, as verified, the interactive and collaborative relationship is fundamental in teaching-learning, becoming the argument for the defense of distance education. 
It is noticeable, therefore, that this work mediated by the TDICs should awaken in the teacher a desire for curiosity, boldness, and innovation in their practices and learning strategies, building a structure centered on teaching, research, and socio-constructivist actions. It is no exaggeration to state that this theme has developed curiosities and integrated teamwork and cooperative learning to value the interaction among students and teachers so that everyone participates actively in building learning.

\section{A Brief History of Distance Education in Brazil and Around the World}

Distance education affects the conventional teaching model since it breaks the space-time relationship, materializing itself through the interaction of communication. In face-to-face learning, teachers are in direct contact with students, and the activities take place at a specific moment for everyone. In distance education, the use of TDICs allows them to develop activities not only at the same time but also at different ones.

Some authors point out that distance education is quite old. For Freitas (2013), for example, its spread occurred along with Christianity when apostle Paul started sending letters to the churches aiming at preaching. The invention of writing is the first technology used in this teaching method, and later typographic technology expanded the scope.

In ancient Greece, and then in Rome, the development of correspondence was made possible by the existence of a network of communication, which would manifest itself in nascent Christianity, acquiring an evolution in the periods of Humanism and the Enlightenment. Therefore, printed books marked the first form of distance education on a massive scale. With the emergence of radio, television, and computer, there was a new dynamic in this teaching method. For these authors, distance education can occur in several ways, such as printed books, mail, radio, television, and the internet. According to Pereira (2003), this method has five generations. The first one had its origin in the 19th century with the offer of correspondence courses in different countries, the second was born in the early 1970s with the creation of the British Open University, and the third appeared at the end of the 1980s, corresponding to the conference distance learning model. The fourth works in virtual learning environments through an interactive, non-linear, and collaborative process. The last is still emerging, but it has the use of computers and the flexible learning model as its basis.

\subsection{Legimitization of distance education in Brazil}

In the first decades of the 20th century, there were some experiences in distance education in Brazil, even with many mishaps and interruptions, using printed material and radio. In 1900, major newspapers in Rio de Janeiro were advertising some isolated correspondence typing courses.

In 1904, an official reference for the emergence of distance education in the country was the installation of the international schools, mainly North American subsidiaries. However, part of the courses offered aimed at workers in the service and trade sectors. Besides, the teaching offered by international schools was by correspondence and the teaching materials sent by the post offices that used the railroads for transportation (ALVES, 2009, p. 9).

The first successful case in Brazil was the foundation of Radio Sociedade do Rio de Janeiro (Radio Society of Rio de Janeiro) in 1923 since its main objective was to provide popular education through the system of radio broadcasting in the country. However, Alves (2009) explains that this model aroused uneasiness in the government elite, and in 1936 the station became part of the Ministry of Education and Health. Also, in the following years, private institutes emerged, which offered distance education courses aimed at professional education.

In Rio de Janeiro and São Paulo, the Serviço Nacional de AprendizagemComercial (National Service of Commerce, SENAC) founded the University do Ar, reaching 318 locations in 1950. The Catholic Church created, in 1959, schools that gave rise to the basic education movement in the city of Natal/RN. Still, in the 1960s, the Federal Government created the Mobral education project, which encompassed the entire national territory through radio. As a result, the military dictatorship that began in 1964, among other attacks on education, began the dismantling of the distance education via radio.

However, with the growing use of television, distance education initiatives are now being used. Alves (2009) states that in 1967 the Brazilian telecommunications code determined what should be broadcast in terms of educational programs by educational radio and television stations. Thus, as distance education stands out, the University of Brasilia (UNB) began offering extension courses in this modality in 1979, becoming a reference in Brazil.

The UNB distance education program became the department of distance education in 1985 linked to the extension decree, and later, in 1989, the Centro de Educação Aberta Continuada a Distância (Center for Open Continuing Distance Education, Cead). In the first period, there were four courses, among which was the first volume of the series O Direito Achado (The Found Law), which is now in its 5th edition with about 12 thousand copies sold (SARAIVA, 1996, p.22). 
Among the significant contributions that LDB 9.394/1996 brought to Brazilian education is the integration of distance education in the legislation. Thus, Alves (2009, p. 11) ensures that:

It was an advance since it has unequivocally enabled not only the operation of undergraduate and graduate courses but also basic education, from elementary to high school, in the traditional modality and in that of young people, adults, and special education. The law had great virtue and indirectly admitted free courses at a distance given by corporate universities and other educational groups (ALVES, 2009, p. 11).

Thus, after regulated by Decree No. 2494/98, in Art. 1, distance education now has an official description.

Distance learning is a form of teaching that enables self-learning, with the mediation of teaching resources systematically organized, presented in different information media, used alone or in combination, and conveyed by the various media. Sole Paragraph - The courses given in the form of distance education will be specially organized, with the flexibility of admission requirements, schedules, and duration, without prejudice, when applicable, to the objectives and curricular guidelines set nationally (BRAZIL, 1998).

Therefore, education is going through a time of transformations, and inserting new technology with new teaching and learning proposals contributes to the breaking of traditional methods. Moreover, the teacher is fundamental in this transformation because, in this education, it is necessary to work as a team and live with different people. It is about the construction of a teaching identity that goes under constant updates, which surpasses itself at every moment. Finally, it is a critical, flexible, and reflective teacher that the current teaching needs.

\section{Challenges Faced by Teachers in the E-Learning Enviroment}

The development of this survey counted on an online questionnaire containing ten questions addressed to teachers from public schools in Ipueiras. It was an attempt to identify and analyze the e-learning context as an educational measure during the Covid-19 pandemic period.

According to Fernandes (2020), teaching challenges in the e-learning context reveal themselves when teachers offer support distantly and flexibly through group activities or individual tutoring. Thus, students share their learning in a semi-presential format. As assured by Silva (2018), e-learning is an educational mode modified by technological advances and characterized by a contemporary education supported by globalized economic policies, which ends up no longer serving essentially educational interests.

The implementation of changes in education and the acceptance of innovations in teaching are gradual, slow, and not infrequently, conflicting processes that face seemingly insurmountable and historically crystallized resistances. When someone questions the type of the current traditional teaching, it is not uncommon to hear that schools are in the $19^{\text {th }}$ century, teachers in the $20^{\text {th }}$, and students in the $21^{\text {st }}$ (PARENTE; VALLE; MATTOS, 2015, p. 15).

When saying that teachers are a century ahead of students, one realizes that there is an attempt to hold students responsible for the poor quality in Brazilian education. However, it is the students who are a century ahead of their teachers since most of them belong to the $\mathrm{Z}$ generation. Another questionable point in this statement is to say that schools are in the $21^{\text {st }}$ century by analyzing their physical structure, the available resources - especially public schools - and the approaches used, it seems that they are the ones that never left the industrial model of the $19^{\text {th }}$ century.

With so many differences between the subjects and the teaching-learning space, it is a challenge for many teachers to fit into the context of virtual education, in which students already arrive with knowledge acquired in their social coexistence and through the numerous technological devices available today. It is up to teachers to constantly improve themselves, acquiring knowledge within their field of work. As an example, the characteristics of hybrid teaching are a way of inserting different students in the e-learning context, bearing in mind that not everyone learns in the same way. Therefore, the student follows an education focused on the different teaching modalities, and one of them is online or distance education.

The models, if once they served as guides, today they are questioned and do not realize the new, the never-lived. Never imagined by our ancestors - distance education - in its irrepressible advances, the new educational, prodigal, and successive technology not only fascinates but also terrifies. The changes destabilize old institutions and challenge certainties constructed during a history (PARENT; VALLE; MATTOS, 2015, p. 11).

Thus, the distance education context requires new parameters for the work because of technological advancement. It is essential to understand that humans are experiencing a pandemic caused by a virus, which imposes policies of social isolation, and, as a consequence, the reformulation of teaching activities for VLEs, instead of the classrooms. It ends up generating anguish and uncertainty in the teachers who must reformulate their teaching methods. In this sense, distance education serves to reflect daily educational practices, allowing the teacher to enter society as a reflective and collaborative professional. The problem for this is to question if the current teacher training prepares them to deal with situations alike. 


\subsection{Distance Education: E-Learning}

Remote activities are a guarantee for autonomy, engagement, and interactivity in educational environments. It is essential to assume that distance education aims to facilitate contact among teachers and students, allowing a spatial displacement, often difficult in reality in person. Regarding the role of the student in e-learning, Marcílio (2019) states that it is a type of distance learning anchored in information technology and mediated by the teacher. Elearning is not only characterized by the use of technology but also by self-learning and cooperation. Neto (2012) says that e-learning made it possible for someone to study anywhere and anytime with the support of contents and activities developed. E-learning, possible by the progress of the world computer network, is a process of synchronous and asynchronous learning, which can occur through various digital media.

Wojcicki (2019) declares that e-learning is an integral school experience in which students divide their time into activities in a physical and remote space. It is no exaggeration to state, however, that this teaching model differs from the reverse classroom model, as students do not attend in a physical school environment during the week. Elearning provides students with immediate feedback, making them the protagonist of their learning. In the words of the author, e-learning refers [...] to a new way of learning, a combination of self-instruction, directed study, and cooperation (WOJCICKI, 2019, p. 122).

By its nature, e-learning is highly dependent on digital technology, both for the production of courses and classes in this format and for their distribution, management, support, and monitoring. For the application of this modality, it is necessary to count on technological resources that go far beyond those necessary to produce didactic materials in digital format. Among these resources, virtual learning environments and management and control systems stand out. (NETO, 2012, p. 123).

The author makes clear the interdependence of resources for distance education, that is, not only applications that develop didactic material of specific contents but also space where these materials - and other forms of interaction - can happen. Perhaps, the reason why e-learning is still much criticized when compared to face-to-face classes is that it is up to the teacher to know the available resources and integrate them in different ways, depending on their teaching objectives. Hence, there is the need to be more than a transmitter of accumulated knowledge, but to be a mediator of shared knowledge.

\subsection{Result and discussion}

As informed at the beginning of the section, this survey counted on a virtual questionnaire, previously elaborated using Google Forms (Google application that allows the creation, sharing, and availability of forms), with a link made available to the teachers of the municipal and state schools from Ipueiras-CE. The period of application of the questionnaire and the sending of responses occurred during the months of April and May 2020, totalizing 68 participants. The questions were in three categories of analysis, namely (1) the profile of the participants, (2) the performance in distance education, and (3) the beliefs about e-learning.

\subsubsection{Profile of the participants}

Questions about the teaching field and gender served to know the profile of the interviewees. Since the survey aimed at the participation of public school teachers in the municipality of Ipueiras, it did not take into consideration two answers from elementary school teachers from private schools and one from higher education from a private institution, totalizing 68 answers. Regarding gender, $61.8 \%$ of the teachers are female, and $38.2 \%$ are male. As for the teaching field, $55.9 \%$ of the teachers are in public schools, $22.1 \%$ are in state schools, and $22.7 \%$ are in other areas of action.

Figure 1 presents an overview of the researched audience regarding the age group. As shown, 39\% of the respondents are between 31 and 40 years old, $31 \%$ between 41 and 50 years old. The youngest teachers, between 20 and 30 years old, comprise $21 \%$ of the interviewees, and only $9 \%$ are between 51 and 60 years old.

Figura 1: Faixa etária dos professores.

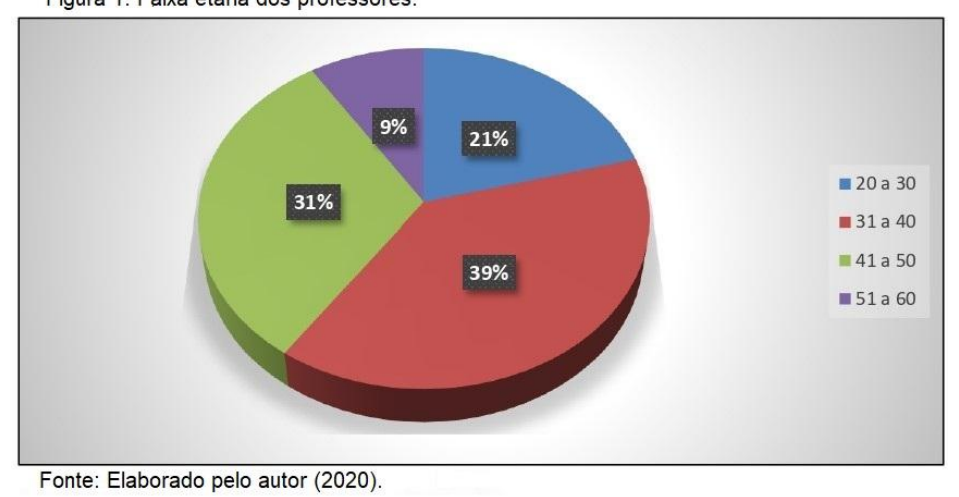


Based on the information presented, it is noticeable that most teachers go through a period of technological changes. Consequently, these teachers stand out in the context of the current health crisis concerning technological insertion because they are prone to be easily converted to the designs of information and communication technologies.

Concerning the time spent working in the teaching profession, Figure 2 below shows that $41 \%$ of these teachers work between 1 and 10 years in the classroom, 32\% work between 11 and 20 years, and 27\% have taught for over 21 years.

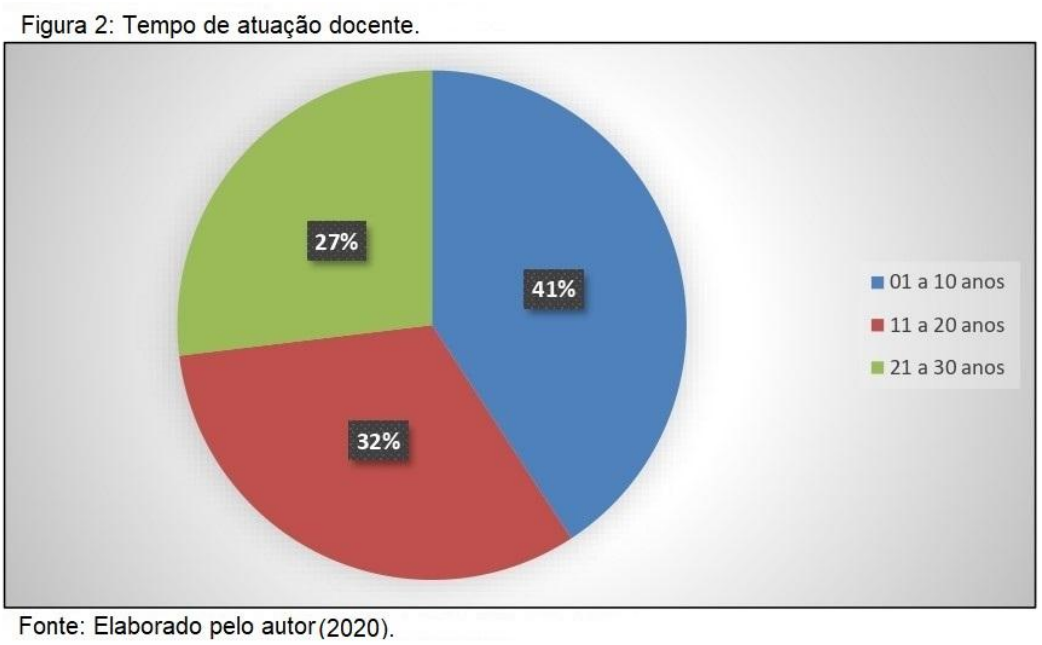

From the data obtained, most of them have vast experience in the classroom. However, it is important to point out that at this time of transformations in the way teachers work, imposed by distance education, they meet methodological challenges since they have taught face-to-face during their teaching career. In other words, teachers who have been working for over 11 years, which is equivalent to $64.9 \%$, find it hard to adapt themselves to elearning. These are challenges directly associated with the technological infrastructure used by teachers, as well as changes in the way schools organize themselves in this exceptional period of human history, which proves a lack of initial and continuing training in the use of technology applied to education.

\subsubsection{Working with e-learning}

In analyzing the educational measures for the implementation of e-learning, what concerns is the accessibility to technological resources by the interviewed teachers. About this, $91.2 \%$ of the interviewees informed that they have personal internet in their homes. Besides, $79.4 \%$ said they use a smartphone, and $63.2 \%$ said they use a notebook in the current distance education, compared to $22.1 \%$ who have a desktop computer to assist their activities. It is worth mentioning that, even with a significant number of teachers with access to several technological resources, it is not perceived quality in virtual classes in this pandemic period, according to the data below.

When asked about which didactic activities they have performed or have been performing during this period of quarantine, it was possible to realize that the difficulties encountered are not only technical but also pedagogical.

Figura 3: Atividades didáticas realizadas no período de quarentena.

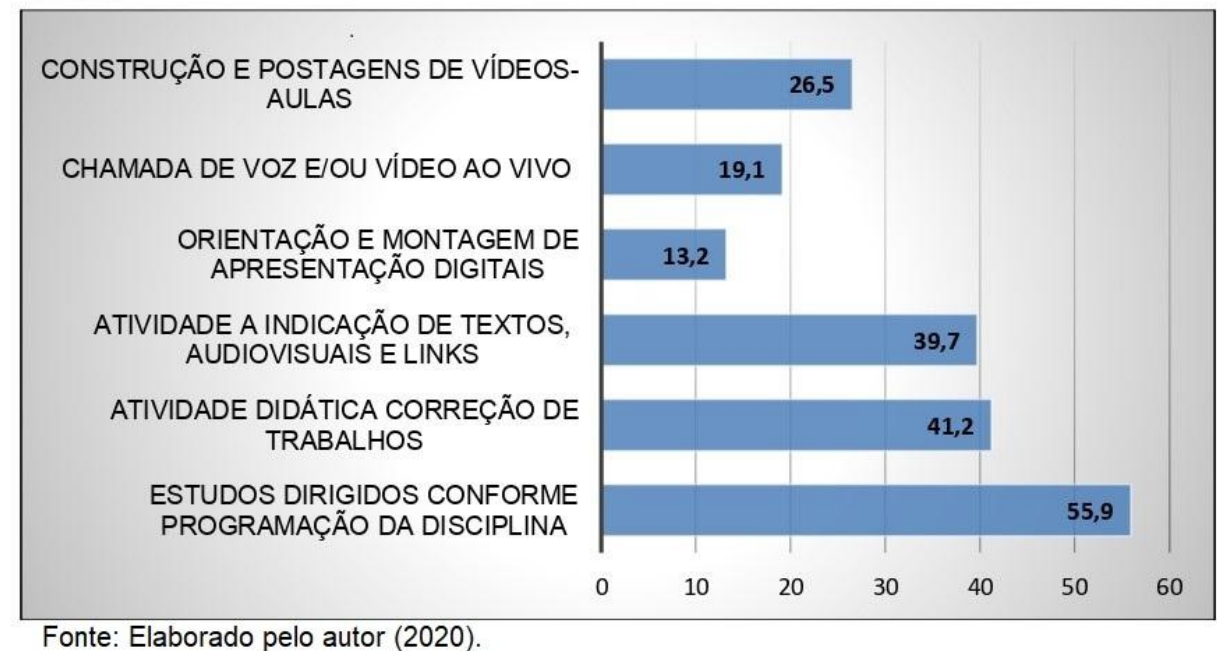


As seen in Figure 3,55.9\% of teachers use directed studies according to the schedule of their subjects, and $41.2 \%$ usethe correction of works as a didactic activity. The latter group corresponds to the transposition of face-to-face teaching to the virtual environment without any adaptation for the use of educational technology.

Regarding the use of virtual interaction, only $19.1 \%$ uses voice calls or live videos for virtual classes, and an even smaller percentage $(13.2 \%)$ stated that they perform orientation and create digital presentations. This indication corroborates what has been presented in the paragraphs above since the activities imply a mediating posture on the part of the teachers. That is, $39.7 \%$ of teachers who use the indication of texts, audiovisuals, and various links, together with the $26.5 \%$ who said they use the construction and posting of video lessons of their authorship, justify a unilateral position in the exposure of content, characterizing a model of banking education (FREIRE, 2011).

Since teaching is not transferring knowledge but creating the possibilities for its production or construction (FREIRE, 2011, p. 24), the data above demonstrate that although the education in Ipueiras tries to fit into the context of distance education at this pandemic period, some teachers have not overcome some challenges yet. Figure 4 confirms it.

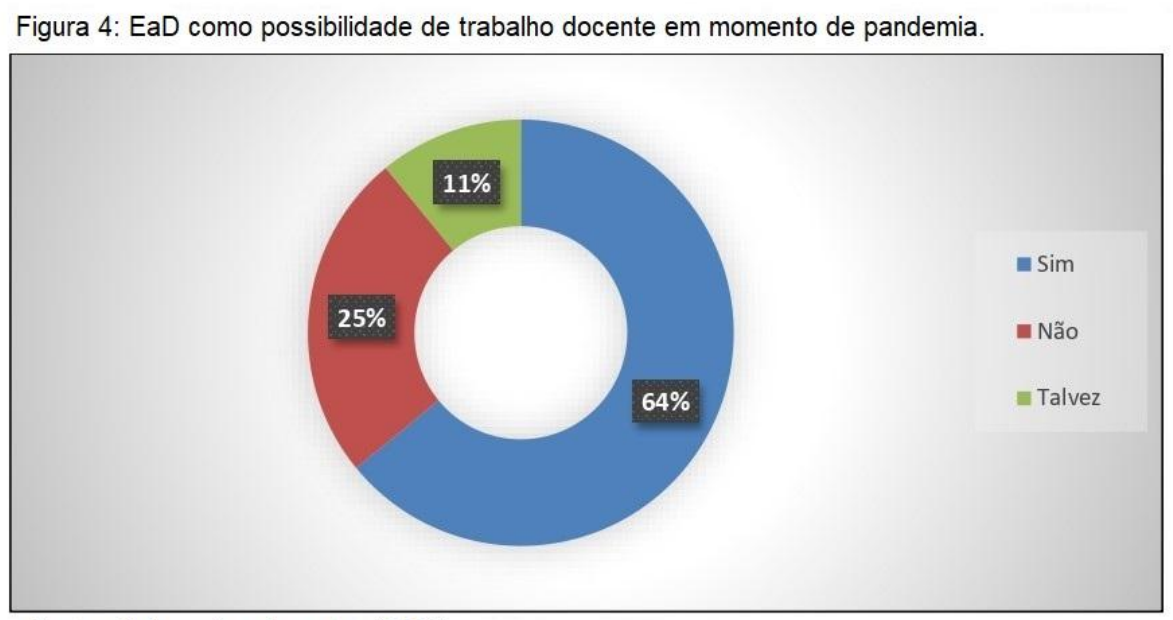

Fonte: Elaborado pelo autor (2020).

Although $64 \%$ of teachers say that e-learning represents a possibility of continuing activities, $25 \%$ doubt that this educational modality can contribute to significant learning, and $11 \%$ do not believe in the effectiveness. This data relates to the next category of analysis, the beliefs about this method, which, in most cases, is what underlies the teaching practice of basic education teachers.

\subsubsection{Beliefs about e-learning in Ipueiras}

Regardless of the opinions on the effectiveness of distance education, the teachers interviewed consider the knowledge of the potential of digital resources indispensable. However, this pedagogical practice relates directly to the reflexive development of each subject inserted in the current context of a pandemic crisis.

Considering the teachers who believe in the possibility of effective distance teaching for the learning of school contents, there has been an investigation on the reasons that influence such effectiveness. Figure 5presents the main results.

Figura 5: Crenças sobre o ensino remoto no município de Ipueiras/CE.

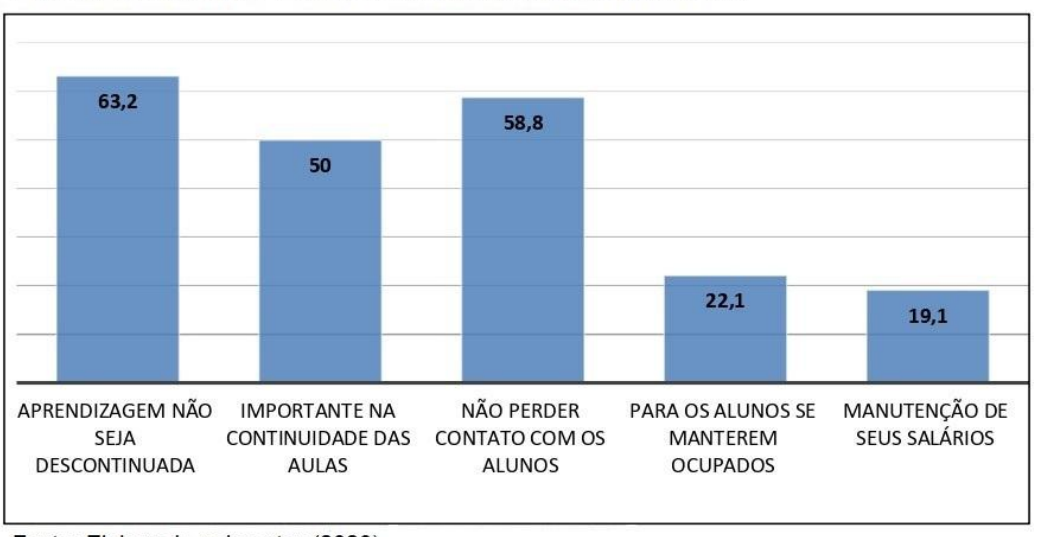

Fonte: Elaborado pelo autor (2020) 
The most significant factors for the effectiveness of distance teaching are related to the contact among teacher, student, and school content. That is, the teachers believe that this way of teaching and learning, even with the challenges imposed, can generate knowledge on the part of students and a new form of teaching for teachers. In a considerably smaller proportion, it is the possibility of keeping students simply busy during social isolation, and the concern with maintaining wages.

Teachers who doubted the effectiveness of e-learning revealed the difficulties that made them position themselves in this way. Figure 6 presents that $27.9 \%$ of teachers find that students are having trouble maintaining concentration, and more than just the exposure of content is necessary to stimulate them.

Figura 6: Entraves para a eficácia da aprendizagem remota.

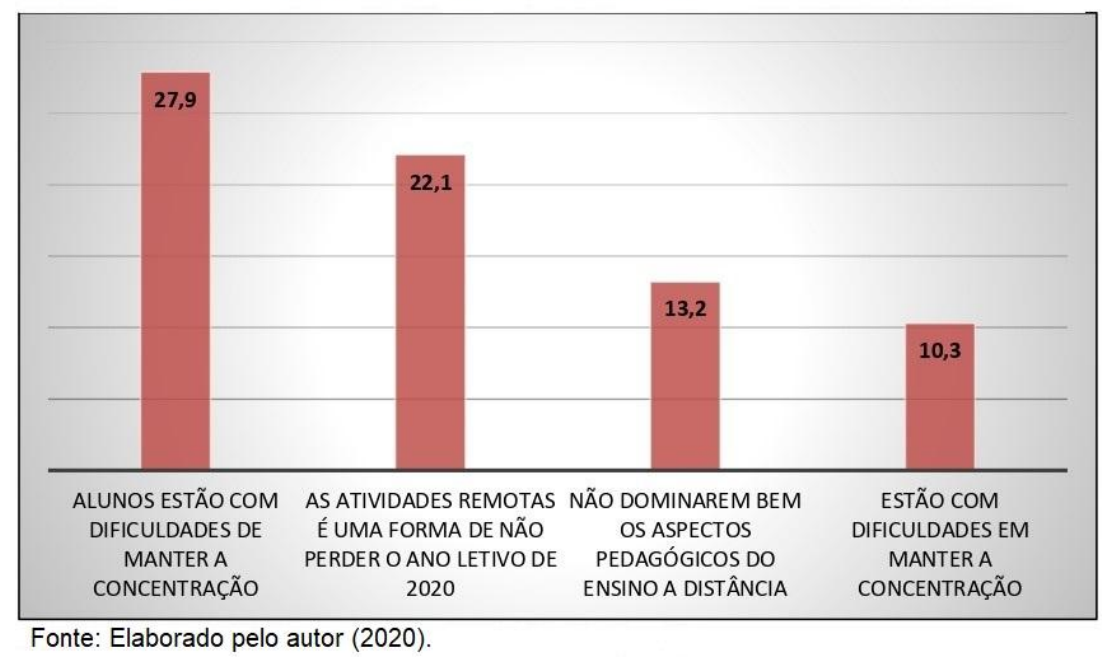

A slightly smaller number of teachers who have positioned themselves fearful of remote teaching believe that virtual activities are simply a way not to miss the school year. Besides, they add that the decisions made by school agencies and institutions were concerned with the continuation of pedagogical activities without adequate professional training to familiarize teachers with technological resources.

Approximately half of these teachers recognized that they did not master the conditions for distance teaching and were not able to concentrate on the point of teaching as before the current crisis. In other words, the technical, emotional, and psychological factors caused by the covid-19 pandemic crisis are an additional issue.

At last, teachers who do not believe in the effectiveness of remote teaching expressed the reasons that lead to this positioning. The first is that they do not know about the potential of distance education, the second is thatsome students do not have technological devices to keep up with the classes, and also the difficulty of concentration for students.

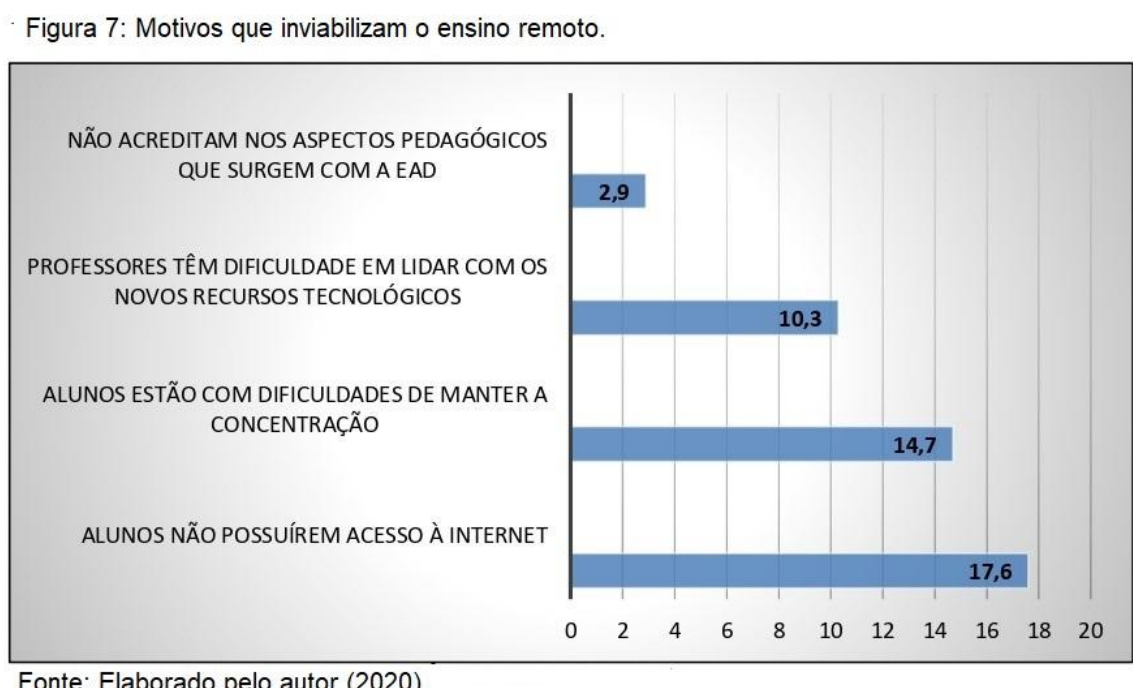

As suggested by Figure 7, only $2.9 \%$ of respondents recognize that digital technology applied to education has no effect. It means that, of all the teachers participating in this research, a small number discredits in remote education. 
These data lead us to conclude that the problems faced by teachers with regard to teaching activities carried out remotely in this period of the pandemic are more related to misinformation and lack of training than to the inefficiency of technology applied to education.

\section{Final Considerations}

The interactive and collaborative relationship is fundamental in the process of distance education and should awaken in teachers the desire to innovate their teaching practices and strategies. Thus, the results of this study made it possible to identify questions about remote teaching in the public schools of the municipality studied and about the beliefs of teachers about this type of teaching.

Initially, many teachers still have difficulties in dealing with this moment of transformations in education, with the insertion of new technology in the educational context. Besides, most of the participants use activities that represent the transposition of a non-dialogue and non-significant class, which used to take place in real classrooms. Finally, for a large part of the teachers interviewed, the difficulty in accessing quality internet and technological equipment are factors that hinder learning - which reflects in the transfer of school failure to students or institutions. Therefore, it is essential to think of alternatives that can include students and teachers, such as financial incentive programs for the acquisition of equipment and good quality internet, as well as training and improvement courses that enable the use of educational technology in basic education. In this way, the $21^{\text {st }}$-century school will be open to a new normal in education.

As a consequence, the understanding of e-learning, discovered by many teachers at this time of global pandemic crisis, may enable new measurements for the teaching-learning process in post-pandemic education. It would mix elements of the face-to-face and remote modalities that allow, perhaps, after 20 years, to take the first educational step of the $21^{\text {st }}$ century.

\section{References}

ALVES, J. R. M. The history of distance education in Brazil. In: LITTO, F. M.; FORMIGA, M. M. M. Distance education: the art state. São Paulo: Pearson Education, 2009.

BRASIL. DecreeNo 2.494, fromFebruary 10, 1998. Regulate Article 80 of LawNo 9.394, from December 20, 1996, that establishestheguidelinesfor the national education. Brasília: Presidency of the Republic, 1998.

CARRARA, R. M. Teachers training for distance education:an initial reflection on teaching in Brazil. 1. ed. Curitiba: Appris, 2016.

FERNANDES, F. Digital transimissions and interfaces in education. São Paulo: Senac, 2020.

FREIRE, P. Pedagogy of autonomy: knowledge needed for educational practice. São Paulo: Paz e Terra, 2011.

FREITAS, M. D. C. D. Distanceeducation. In: ALMEIDA, M. G. D.; FREITAS, M.D.C.D. Virtualization of relationships: a challenge for school management. Rio de Janeiro: Brasport, v. III, 2013.

KENSKI, Vani Moreira. Technologyandteaching time. 1. ed. Campinas-SP: Papirus, 2013.

MARCILIO, D. S. Problem-based learning. São Paulo: SENAC São Paulo, 2019.

MOORE, Michael G., KEARSLEY, Greg. Distance education: a view of the system. São Paulo: Thomson Learning, 2007.

NETO, A. S. Scenarios, and distance education modalities. 1. ed. Curitiba, PR: IESDE Brasil, 2012.

PARENTE, C. D. M. D.; VALLE, L. E. L. R. D.; MATTOS, M. J. V. M. D. Teacher training and the challenges in the face of social, political, and technological changes. Porto Alegre: Penso, 2015.

PEREIRA, Eva W. Distance education: conception and development. LinhasCríticas Magazine, Brasília, V.9, n. 17, jul/ dez. 2003, p. 197-212. Available at<http://periodicos.unb.br/index.php/linhascriticas/article/view/ 3166/2854>. Acess: 20/06/2019.

SARAIVA, Terezinha. Distance education in Brazil: lessons from history.Brasília, ano 16, n. 70, abr/jun 1996, pp. 17-27.

SAVIANI, D. History of pedagogical ideas in Brazil. 4. ed. Campinas-SP: Autores Associados, 2013.

SILVA, R. L. D. Distance education:solutionfor the legalizationof homeschooling. 1. ed. Joinville-SC: Clube de Altores, 2018.

TARDIF, M. Teacher knowledge and professional training. 17. ed. Petrópolis-RJ: Vozes, 2014.

WOJCICKI, E. Moonshots in education: hybrid teaching and collaborative learning in the classroom. São Paulo: Panda Books, 2019. 